Article

\title{
Methods of Predicting the Effectiveness of Hydrochloric Acid Treatment Using Hydrodynamic Simulation
}

\author{
Ivan Putilov, Sergey Krivoshchekov* ${ }^{\mathbb{D}}$, Kirill Vyatkin, Aleksandr Kochnev and Kirill Ravelev \\ Perm National Research Polytechnic University, Mining and Petroleum Faculty, 614990 Perm, Russia; \\ Ivan.Putilov@pstu.ru (I.P.); Kirill.Vyatkin@pstu.ru (K.V.); Alex.Kochnev@pstu.ru (A.K.); \\ Kirill.Ravelev@pstu.ru (K.R.) \\ * Correspondence: Krivoshchekov@pstu.ru; Tel.: +7-(342)-219-83-07
}

Received: 12 June 2020; Accepted: 10 July 2020; Published: 14 July 2020

\begin{abstract}
The article describes the original technique of predicting the effectiveness of hydrochloric acid treatment of the bottom hole zone of a carbonate reservoir. The technique consists in determining the technological effectiveness of the oil recovery stimulation procedure at productive wells using hydrodynamic simulation based on the calculated value of skin factor change. In the course of the study, a number of parameters affecting the intensity of flow coefficient decline in the near-wellbore zone during acid treatment have been established. The paper presents a comparison of data on the actual change of the skin factor after acidizing jobs at the fields of Perm Krai (Russian Federation) and the calculated values obtained using the presented technique. This scientific research includes an example of practical application of the proposed technique for the target well of the Kokuyskoye oil field in Perm Krai, its results with a minor deviation coinciding with the actual values of the flow rate. In the conclusion to the study, it is noted that using the proposed technique, recommendations can be provided on the selection of acid composition and technology of its injection into formation for the preliminary evaluation of the cost effectiveness of the designed procedure.
\end{abstract}

Keywords: hydrochloric acid treatment; hydrodynamic simulation; skin factor; production prediction; effectiveness evaluation

\section{Introduction}

The bottom-hole zone (BHZ) condition deteriorates during the entire well operation due to damage of flow channels with different particles. Since the contaminated area near the well reduces the reservoir-to-well hydrodynamic connectivity, the well productivity does not reach the maximum possible value, while carbonate rocks are characterized by low flow properties per se. The necessity of detailed study of properties of carbonate reservoir and methods of their development is propelled by the presence in them of one-third to half of hydrocarbon reserves worldwide (Khizhnyak et al., 2015 [1]).

Hydrochloric acid treatment (HAT) is the most effective and cost-efficient method of oil production stimulation at the deteriorated state of near-wellbore zone (NWZ) as of today (Aidagulov et al., 2019 [2]; Moid et al., 2020 [3]; Ridner et al., 2019 [4]; Sarmah et al., 2019 [5]; and Singh et al., 2019 [6]). However, acidizing does not always produce the planned results due to insufficient consideration of key factors such as flow properties of reservoir, bottom-hole zone structure, and its parameters before well stimulation, as well as their behaviour in the process of treatment with acid composition (AC). 
The success of chemical treatment in the bottom-hole zone is demonstrated by a negative change in the skin factor, which is calculated from the Hawkins' formula (Equation (1)) (Hawkins, 1956 [7]):

$$
S=\left(\frac{k}{k_{d}}-1\right) \cdot \ln \frac{r_{d}}{r_{w}}
$$

Equation (1) takes into account the difference in permeability of the near-wellbore and far field zones (Figure 1), based on which, the degree of the bottom-hole zone contamination is evaluated.

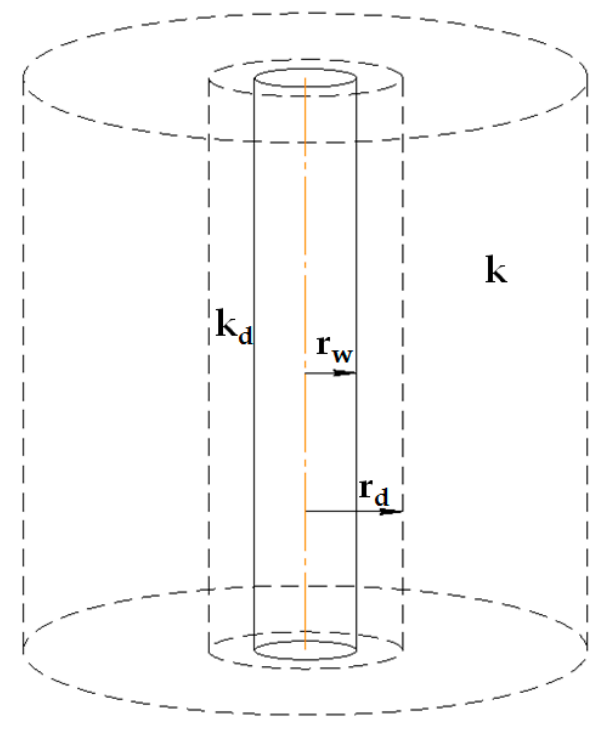

Figure 1. Schematic of near-wellbore and far field formation zones.

The acid treatment process is considered to be quite complex and inexplicable in the details of the process of dissolution of minerals from carbonate reservoir rocks by hydrochloric acid. Therefore, when forecasting the technological effect of the considered method of stimulation of hydrocarbons production, there are many issues (Ali et al., 2019 [8]) arising associated with the inability to forecast the nature of changes in the void space of the productive formation near the well. Conducting flow studies on core samples under reservoir conditions is one of the ways to address these issues (Abdrazakov et al., 2019 [9]; Hall-Thompson et al., 2020 [10]). Computer tomography allows to determine the change of pore space, namely, the size and position of the channel that has broken through the sample, which is called a "wormhole." However, in the article (Gurbatova et al., 2013 [11]), the authors point to the unreliability of the results obtained during the studies on standard samples of rock formation using a flow unit in relation to the real acid treatments at the oil field, which is referred to high anisotropy of reservoir properties of carbonate oil- and gas-saturated rocks (Farooq et al., 2019 [12]).

Most of scientific research works is aimed at studying the process of "wormholing" forming in rocks under the effect of acid compositions. The authors of the work (Kanevskaya and Novikov, 2018 [13]) have analysed the existing models describing this process in detail. The application of the studied models is considered in the publication (Trushin et al., 2019 [14]), where semiempirical models of Gong, Furui, and Buijse have been used, which allow to predict the direction of AC spreading in the pore space of $\mathrm{BHZ}$ and to estimate the increase in permeability coefficient in this area. The obtained flow characteristics allow to calculate additional fluid inflow using available formulas of plane radial flow of fluids to hydrodynamically imperfect wells due to reduction of additional flow resistance provided by change in the skin factor.

An example of initial evaluation of the hydrochloric acid treatment effectiveness on carbonate rocks is also given in the work (Khuzin et al., 2019 [15]); its authors have developed an acidizing effect simulator that allows to calculate changes in the structure of the rock near the well. The software is based on the development of a "wormhole" in the process of AC treatment, as a model for which a 
semiempirical model proposed by Buijse and Glasbergen was used (Buijse and Glasbergen, 2005 [16]). This invention integrates all permeability and porosity properties of oil-saturated interlayers into the model and simulates their change when simulating AC injection. The success of the HAT procedure is also evaluated by reducing flow resistance coefficient in the NWZ.

Proceeding from the analysis of publications, it is possible to draw a conclusion that the existing methods of acid treatment effectiveness prediction are largely based on the determination of the skin factor change, which, in turn, changes with the increase of NWZ permeability coefficient. For a more accurate evaluation of the effectiveness of the designed geotechnical procedures, the hydrodynamic simulation is applied, which allows to calculate and evaluate the increase in well productivity. In Perm Krai, when designing the acidizing effect on oil producing wells, nowadays in most cases, the field data from previously conducted procedures of oil recovery stimulation in the same field, or in analogue fields, are included as a basis. This accounts for the discrepancy between the actual and predicted values of oil flow rate due to the wrong approach to the creation of the HAT model carried out when interpreting the degree of change in the skin factor from previous chemical treatments of reservoirs.

\section{Materials and Methods}

To predict the effectiveness of hydrochloric acid treatment of carbonate deposits this work proposes hydrodynamic simulation to determine the gain in incremental oil production and duration of the effect, based on theoretical calculations of the decrease of the skin factor. Daccord and Lenormand's experiments in the study of the interaction of $\mathrm{AC}$ and rock have brought to an empirical equation (Equation (2)) allowing to evaluate the change in the skin factor after the acid effect on the bottom-hole zone (Daccord et al., 1989 [17]):

$$
\Delta S=-\frac{1}{d} \cdot \ln \left(1+A c \cdot\left(\frac{q}{D \cdot h}\right)^{-1 / 3} \cdot \frac{b \cdot V}{\pi \cdot h \cdot m \cdot r_{w}^{d}}\right)
$$

When calculating the fractal dimension $d$, the quantitative content of limestone and dolomite in carbonate rock should be taken into account. Below is an equation for calculating the value of fractal dimension (Equation (3)):

$$
d=\frac{1.6 \cdot x+2 \cdot y}{x+y}
$$

In order to determine the percentage of calcite and dolomite in the rock, it was necessary to carry out laboratory studies of the rock, using carbonate metering device, such as KM-04M that allowed to determine the mass content of calcite, dolomite, and insoluble mineral residue in the crushed rock sample. Figure 2 shows the image of the carbonate metering device KM-04M used in the present research for quantitative determination of calcite, dolomite, and insoluble mineral residue in the rock under study.

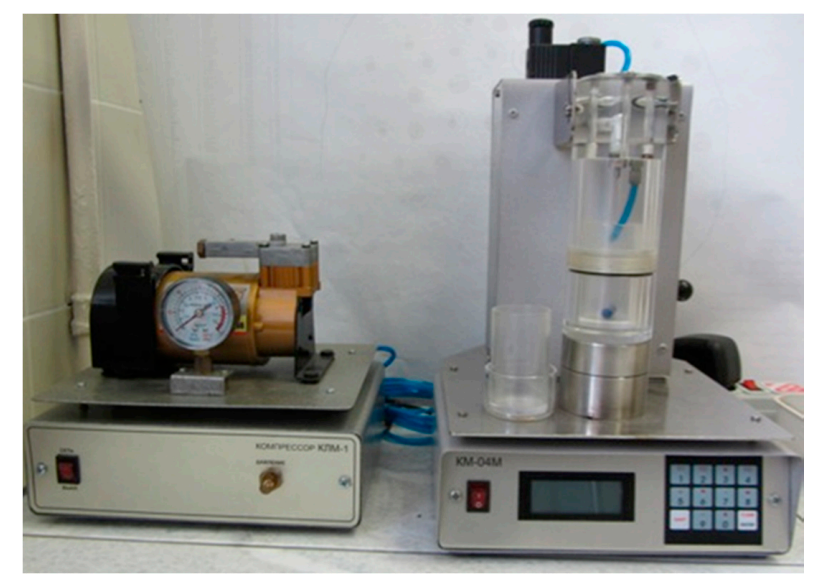

Figure 2. KM-04M carbonate metering device. 
The acid value was determined by the ratio given in Equation (4):

$$
A c=\frac{m \cdot C_{H C l}}{C_{r o c k} \cdot \vartheta}
$$

The concentration value of the reservoir depends on the percentage ratio of limestone and dolomite in the rock under study. It was determined by the following equality (Equation (5)):

$$
C_{\text {rock }}=\frac{\mathrm{C}_{\mathrm{CaCO}_{3}} \cdot x+\mathrm{C}_{\mathrm{CaMg}\left(\mathrm{CO}_{3}\right)_{2}} \cdot y}{x+y}
$$

To determine the concentrations from reference data, the values of molecular masses of the reacting rocks, i.e., straight limestone and dolomite, and hydrochloric acid solution, were used. The concentration of the corresponding substance was calculated using Equation (6):

$$
C=\frac{\rho}{M}
$$

According to GOST 3118-77 standard, the density of hydrochloric acid should be 1150-1190 g/L, therefore, a mean value of $1170 \mathrm{~g} / \mathrm{L}$ was used for the concentration calculation. According to the reference data, the density of calcite and dolomite were taken to be equal to 2710 and $2880 \mathrm{~g} / \mathrm{L}$, respectively, and their molecular masses were taken to be equal to 100.086 and $184.399 \mathrm{~g} / \mathrm{L}$, respectively.

According to the reaction equations, the stoichiometric coefficient for limestone was taken to be equal to 2, and 4 for dolomite, so the reservoir stoichiometric coefficient was determined like the fractal value (Equation (7)):

$$
\vartheta=\frac{\vartheta_{\mathrm{CaCO}_{3}} \cdot x+\vartheta_{\mathrm{CaMg}\left(\mathrm{CO}_{3}\right)_{2}} \cdot y}{x+y}
$$

This work proposes to estimate the acid diffusion coefficient using the Stokes-Einstein equation (Chordia and Trivedi, 2010 [18]) that is widely used to determine the $D$ value in fluids (Equation (8)):

$$
D=\frac{k_{B} \cdot T}{6 \cdot \pi \cdot \mu \cdot r}
$$

One of the variants for determining the dynamic viscosity of AC was the method used as per GOST 33768-2015 standard, using VPZh-4 viscometer, shown in Figure 3. The radius of the diffusing particle can be determined by means of a binocular microscope.

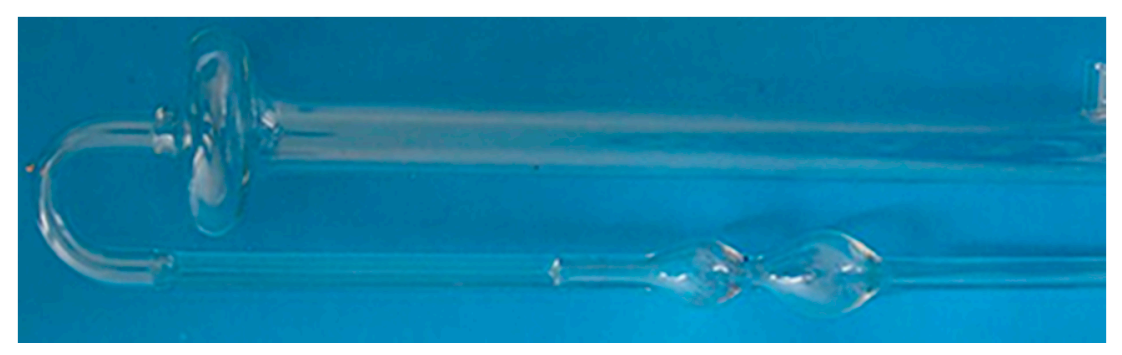

Figure 3. VPZh-4 viscometer. 
For the sake of further convenience, Equations (2)-(8) were grouped and transformed into Equation (9):

$$
\begin{aligned}
& \Delta S \\
& =-\frac{x+y}{1.6 \cdot x+2 \cdot y}
\end{aligned}
$$

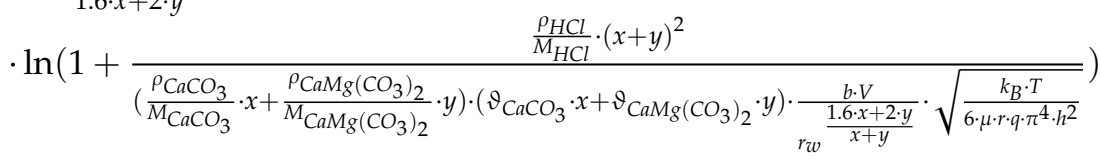

By substituting constants in Equation (9), Equation (10) was obtained:

$$
\Delta S=-\frac{x+y}{1.6 \cdot x+2 \cdot y} \cdot \ln \left(1+\frac{0.0015661 \cdot(x+y)^{2} \cdot V \cdot \sqrt[3]{\frac{T}{\mu \cdot r \cdot q \cdot h^{2}}}}{(27.08 \cdot x+15.40 \cdot y) \cdot(2 \cdot x+4 \cdot y) \cdot r_{w}^{\frac{1.6 x+2 \cdot y}{x+y}}}\right)
$$

When analysing Equation (10), we can conclude that the change in the skin factor after the acidizing effect on the carbonate reservoir depends on a number of parameters given in Equation (11):

$$
\Delta S=f\left(x, y, V, T, \mu, r, q, h, r_{w}\right)
$$

Based on Equation (11), to predict the effectiveness of HAT, the content of calcite and dolomite in the reservoir rock, as well as its current absolute temperature, rheological properties of AC, and the radius of its diffusing particles were determined. It is also necessary to define the perforated formation thickness, the well radius, and the designed amount of AC to be injected into the formation, which can vary widely based on the BHZ condition and the expected effect. After defining these parameters and calculating the skin factor change by Equation (10), the obtained value of $\Delta S$ was inputted into the hydrodynamic model of the production facility. The standard isothermal flow model of the three-phase (oil, water, and gas) three-component (oil, water, and oil-dissolved gas) fluid in pore space was used when building the field hydrodynamic model. Well perforation interval is characterized by the skin factor and "well-to-reservoir connectivity" parameters. When simulating the acid treatment, the calculated change in the skin factor was taken into account and the key technological parameters of the well operation were calculated. As a result of the calculations conducted in the hydrodynamic simulator (e.g., IRAP Tempest or Eclipse), diagrams of changes in the annual oil and water production by the basic variant and after the designed job were built. Based on the change in the annual oil and water production, a conclusion was made on the predicted effectiveness of acid treatment of the target well operating an oil-saturated reservoir with deteriorated condition of BHZ.

\section{Research Results and Obtained Factual Findings on the Predicted Effectiveness Evaluation of Hydrochloric Acid Treatment at the Fields of Perm Krai}

Hydrochloric acid treatments are used in Perm Krai to stimulate oil production from carbonate formations. The work reviews the practice of 18 acidizing jobs at the oilfields in Perm Krai. Using multiple regression analysis, the dependency of additional oil production on a number of parameters has been determined, which can be used to promptly estimate the effectiveness of hydrochloric acid treatment (Equation (12)):

$$
220.0315 \cdot x+1065.9062 \cdot y+195.8524 \cdot S_{1}-116.9743 \cdot Q_{1}-17878.5183=\Delta Q_{\text {cum }}
$$

As shown in Figure 4, the relationship can be characterised as tight, however, this equation is of little practical use $\left(R^{2}=0.70\right)$. 


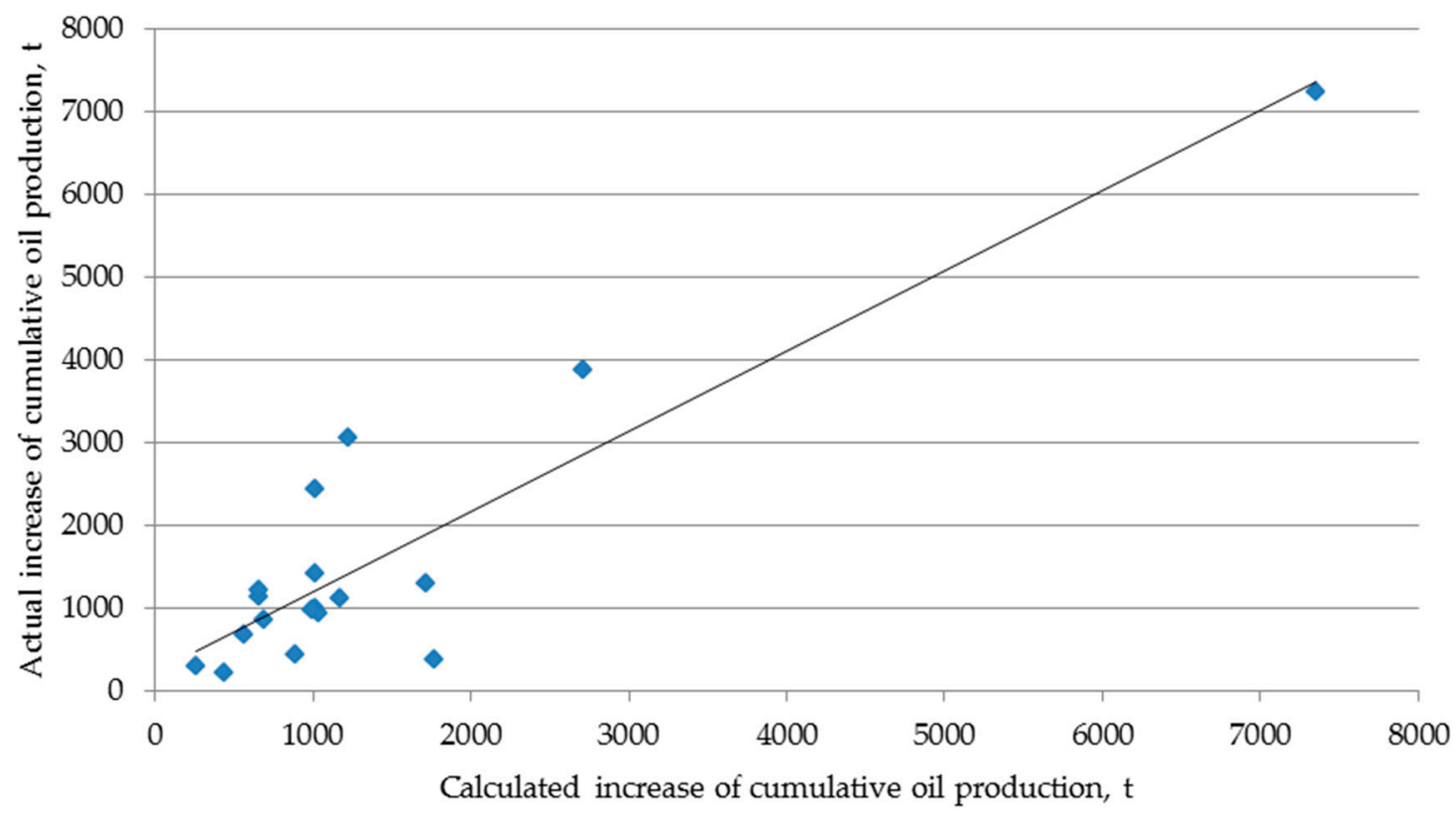

Figure 4. Comparison of actual and calculated increase of cumulative oil production.

To determine the possibility of practical application of obtained Equation (10) for predicting the effectiveness of the designed acid treatment, statistical analysis has been conducted. For each of reviewed procedure, the expected change in the skin factor is determined, calculated based on the presented technique of prediction of change in the skin factor after the HAT job. Table 1 provides a comparison of the actual change in the skin factor for the wells under study and the predicted value obtained using the given technique.

Table 1. Comparison of skin factor actual change with predicted values.

\begin{tabular}{cccccc}
\hline $\begin{array}{c}\text { Job } \\
\text { No. }\end{array}$ & Deposit & Formation & $\begin{array}{c}\text { Skin Factor } \\
\text { Actual Change }\end{array}$ & $\begin{array}{c}\text { Skin Factor } \\
\text { Predicted Change }\end{array}$ & $\begin{array}{c}\text { Deviation, } \\
\%\end{array}$ \\
\hline 1 & Ozyornoye & Bashkirian-Serpukhovian & -3.40 & -3.27 & 3.82 \\
\hline 2 & Unvinskoye & Bashkirian-Serpukhovian & -2.80 & -2.90 & 3.57 \\
\hline 3 & Zmeyevskoye & Tournaisian & -3.20 & -2.94 & 8.13 \\
\hline 4 & Yurchukskoye & Famennian & -2.50 & -2.74 & 9.60 \\
\hline 5 & Yurchukskoye & Bashkirian & -2.70 & -2.53 & 6.30 \\
\hline 6 & Logovskoye & Tournaisian-Famennian & -2.60 & -2.84 & 9.23 \\
\hline 7 & Pavlovskoye & Tournaisian & -2.40 & -2.57 & 7.08 \\
\hline 8 & Shagirtsko-Gozhanskoye & Vereiskian $\left(V_{3} V_{4}\right)$ & -2.90 & -2.71 & 6.55 \\
\hline 9 & Dorokhovskoye & Tournaisian & -2.80 & -2.83 & 1.07 \\
\hline 10 & Pavlovskoye & Tournaisian & -3.00 & -2.96 & 1.33 \\
\hline 11 & Sibirskoye & Bashkirian-Serpukhovian & -2.90 & -2.70 & 6.90 \\
\hline 12 & Churakovskoye & Tournaisian & -2.80 & -2.58 & 7.86 \\
\hline 13 & Rassvetnoye & Bashkirian & -3.10 & -3.26 & 5.16 \\
\hline 14 & Rassvetnoye & Bashkirian & -2.50 & -2.79 & 11.60 \\
\hline 15 & Kurbatovskoye & Tournaisian & -2.60 & -2.77 & 6.54 \\
\hline 16 & Yurchukskoye & Bashkirian-Serpukhovian & -2.80 & -2.68 & 4.29 \\
\hline 17 & Yurchukskoye & Bashkirian-Serpukhovian & -2.90 & -2.64 & 8.97 \\
\hline 18 & Chikulayevskoye & Tournaisian & -2.70 & -2.85 & 5.56 \\
\hline & & & & & \\
\hline & & & & & \\
\hline
\end{tabular}


As it can be seen, the relative errors presented in Table 1 vary in the range from $1.07 \%$ to $11.60 \%$, which is an allowable deviation. For more accurate analysis and determination of the significance of the relationship between the two sets of values, i.e., actual and calculated changes in the skin factor, the main statistical indicators shall be used. As determined by calculations using STATISTICA software, the Student's $t$ test and the achieved significance level constitute 0.079 and 0.937 , respectively, while standard deviations do not exceed allowable value range, as well, i.e., the internal scatter about the mean is insignificant. The conducted analysis indicates the high significance of the relation between actual and design data, which testifies to the effective approach to the prediction of HAT results using the proposed technique.

Comparative analysis of actual and design results has afforded the authors of this work, the assurance in the idea of using Daccord and Lenormand's formula in the basis of predicting the success of acid treatment. An example of the practical application of the proposed technique on the existing well, which consists in determining the HAT effectiveness using hydrodynamic simulation, is given below in this paper.

In July 2019, an oil-producing well of the Kokuyskoye oil field in Perm Krai, entering the Tournaisian strata, was determined as the target facility for the hydrochloric acid treatment job. To evaluate the perfection of the proposed method of predicting the acidizing effectiveness, the authors have presented a comparison of actual and design production rates for the subsequent 6 months of operation of the well under study. Additionally, using Tempest MORE hydrodynamic simulator, a geotechnical procedure was designed, and the technological effect of planned acid treatment of bottom-hole zone for the following 10 years was analysed.

FLUXOCORE-210 (grade P) acid composition was selected as an agent, as it has proved to be excellent in the field experience of oil recovery stimulation methods and has shown good results in laboratory studies presented in the paper (Ravelev, 2019 [19]). According to the results of hydrodynamic studies of the target oil producing well of 15 June 2019, the value of the skin factor was determined as equal to 1.1. The authors calculated the reduction of flow resistance in the near-wellbore zone using the above technique, which allowed to further calculate the increase in the target well flow rate after acid treatment on the hydrodynamic model.

Before acid treatment of the productive formation, in order to eliminate undesirable consequences, it was expedient to carry out laboratory research on the compatibility of AC with fluids inflowing from the target facility. The study of their interaction plays an important role in the design of hydrochloric acid treatment, since in case of poor compatibility, there is a possibility of a high-viscosity emulsion, clots, flakes, and precipitation that result in damage of void space. For this purpose, testing with 15 different ratios of oil, water, and acid composition was performed under laboratory conditions. In the beginning, stable water-oil emulsion from the selected samples of oil and water from the target well under study was obtained; after that, the acid composition under test was added to the obtained emulsion. As a result, the state of the obtained mixture was assessed visually for precipitation and phase immiscibility at several-minute exposure; the obtained mixture was filtered through a 100-mesh sieve with registration of presence/absence of nonfilterable residue. Table 2 illustrates some of the laboratory findings on the compatibility of the acid composition under test with the fluids collected from the target well.

As a result of laboratory research on compatibility of formation fluids with acid composition, it can be concluded that formation fluids and acid composition are well compatible, as in all cases, there were no signs of residue formation during filtration of the obtained mixtures. Therefore, FLUXOCORE-210 composition can be considered applicable to these conditions by the nature of interaction with the fluids. 
Table 2. Results of study of compatibility of formation fluids collected from the target well, with the acid composition under test.

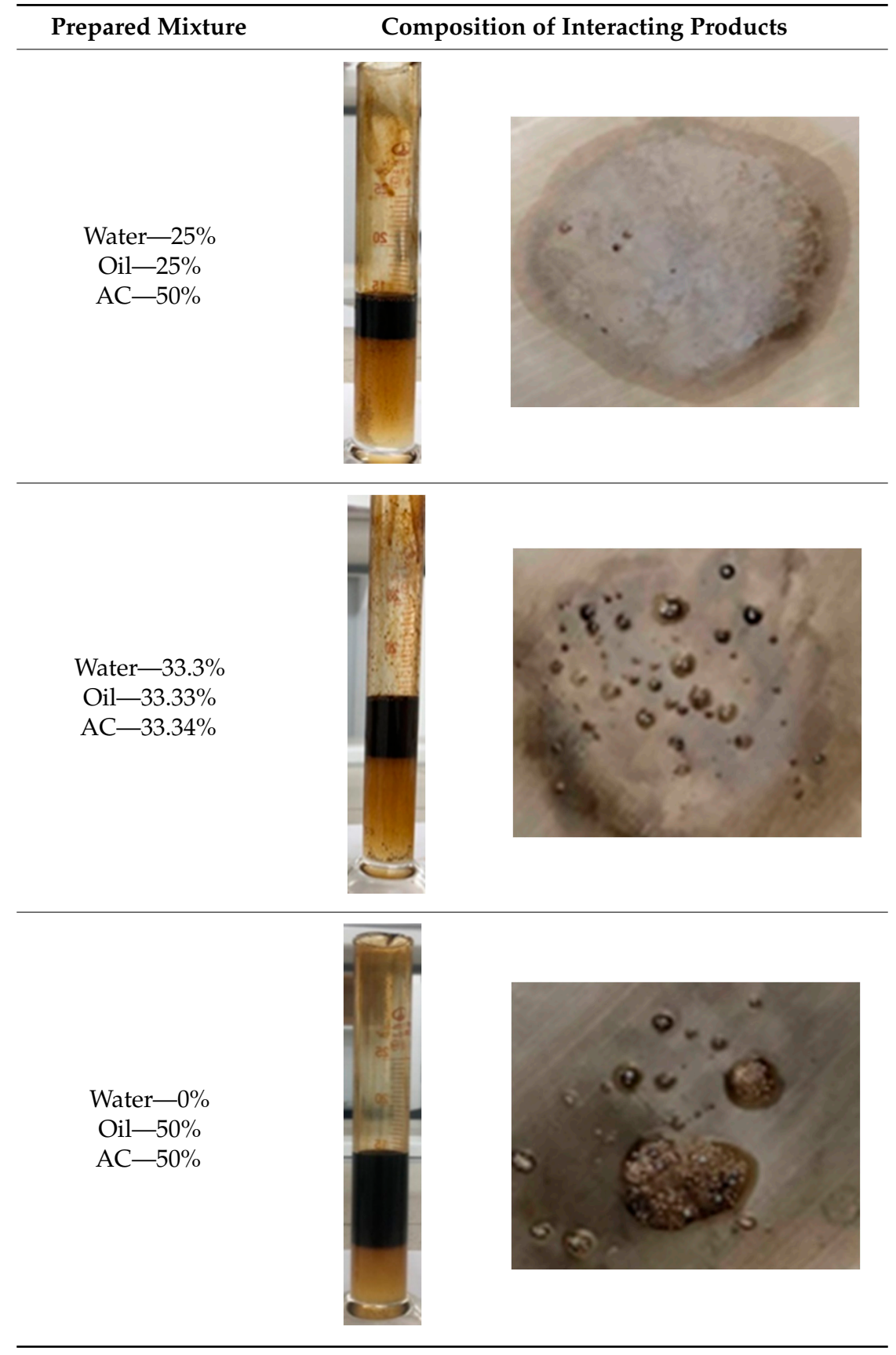

To determine the predicted change in the skin factor from Equation (10), a number of laboratory studies to obtain the initial data for the calculation were conducted. The mass fractions of calcite and dolomite contained in the rock were found to be 89.7 and 1.2\%, respectively, which are typical of the Tournaisian stage in Perm Krai. The viscosity value of FLUXOCORE-210 acid composition, determined as the average of several experiments, was $1.37 \times 10^{-3} \mathrm{~Pa} \cdot \mathrm{s}$. The radius of the diffusing AC particle, as determined with Mikmed-5 microscope, was $1.0 \times 10^{-6} \mathrm{~m}$. This radius is defined as the average of several radii of the particles under study, their values changing within a small range. Figure 5 shows the image of AC particles under microscope as obtained by the authors during the research in the scientific laboratory. 


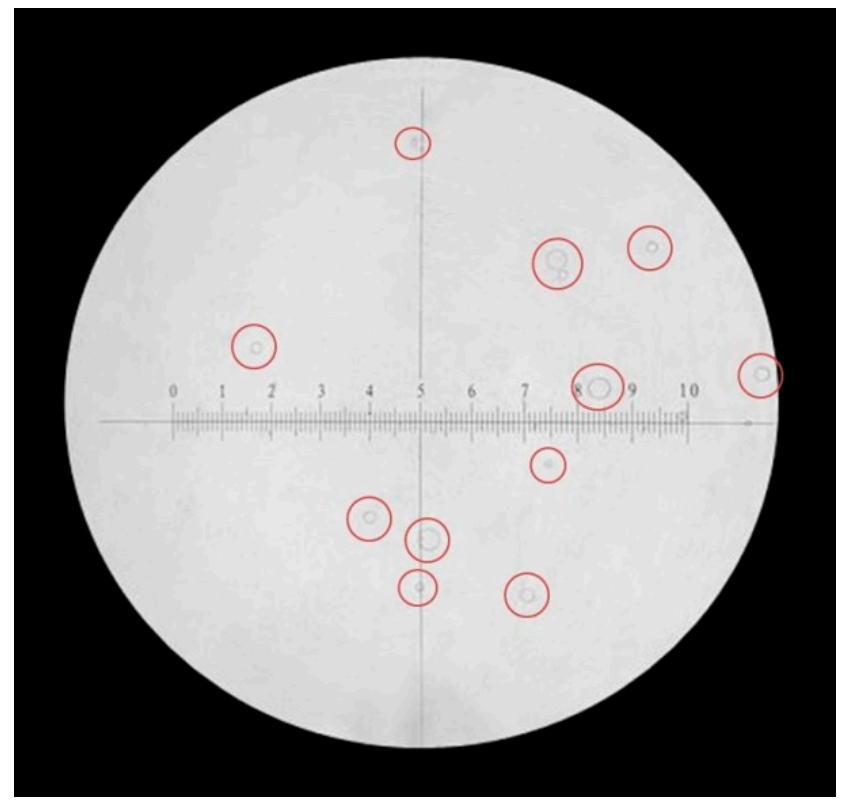

Figure 5. Image of diffusing particles under microscope.

Data on reservoir pressure provides an understanding of the required rate of acid injection into the formation. The HAT process was often carried out using AzINMASh-30 pumping unit. Its technical characteristics are given in Table 3 (Iolchuev and Savenyuk, 2018 [20]; Mishchenko, 2003 [21]).

Table 3. Pumping rate and pressure developed by AzINMASh-30 unit.

\begin{tabular}{ccccc}
\hline \multirow{2}{*}{ Speed } & \multicolumn{4}{c}{ Plunger Diameter, $\mathbf{m m}$} \\
\cline { 2 - 5 } & \multicolumn{4}{c}{$\mathbf{1 0 0}$} \\
\cline { 2 - 5 } & Pumping Rate, L/s & Pressure, MPa & Pumping Rate, L/s & Pressure, MPa \\
\hline II & 2.24 & 50.0 & 3.23 & 34.4 \\
III & 4.28 & 25.9 & 6.16 & 18.0 \\
IV & 6.50 & 17.1 & 9.36 & 11.8 \\
V & 9.78 & 11.3 & 14.08 & 1.9 \\
\hline
\end{tabular}

According to Table 3, the acid composition pumping rate was determined as $6.5 \times 10^{-3} \mathrm{~m}^{3} / \mathrm{s}$. Bottom-hole temperature was $28^{\circ} \mathrm{C}$, as determined from telemetry data. The well diameter was $146 \times 10^{-3} \mathrm{~m}$.

According to geophysical and hydrodynamic studies, the formation operated by the target oil production well is characterized by strong heterogeneity and low permeability. As a result, a large-volume hydrochloric acid treatment (LHAT) is recommended for the best results. In a work (Musabirov et al., 2019 [22]), it is reported that the volume of acid composition per $1 \mathrm{~m}$ of treatment interval varies in the range from 3 to $5 \mathrm{~m}^{3}$ when the LHAT technology is applied for carbonate deposits. The perforated formation thickness in this target well reaches $8 \mathrm{~m}$, therefore, it is necessary to inject acid in the volume of $40 \mathrm{~m}^{3}$ to maximize the BHZ permeability.

When all of obtained values are substituted in Equation (10), the calculated predicted decrease of the skin factor is 4.0, which has a significant impact on changes in the amount of fluid recovered from this well. The conducted calculation of the predicted value of the skin factor after acid treatment of the target facility under study, which equals $S=1.1-4.0=-2.9$, allows to perform the comparative analysis between the actual values of the well oil and fluid flow rate obtained over 6 months and those predicted using hydrodynamic simulation, as given in Table 4. Figure 6 illustrates the hydrodynamic model. 


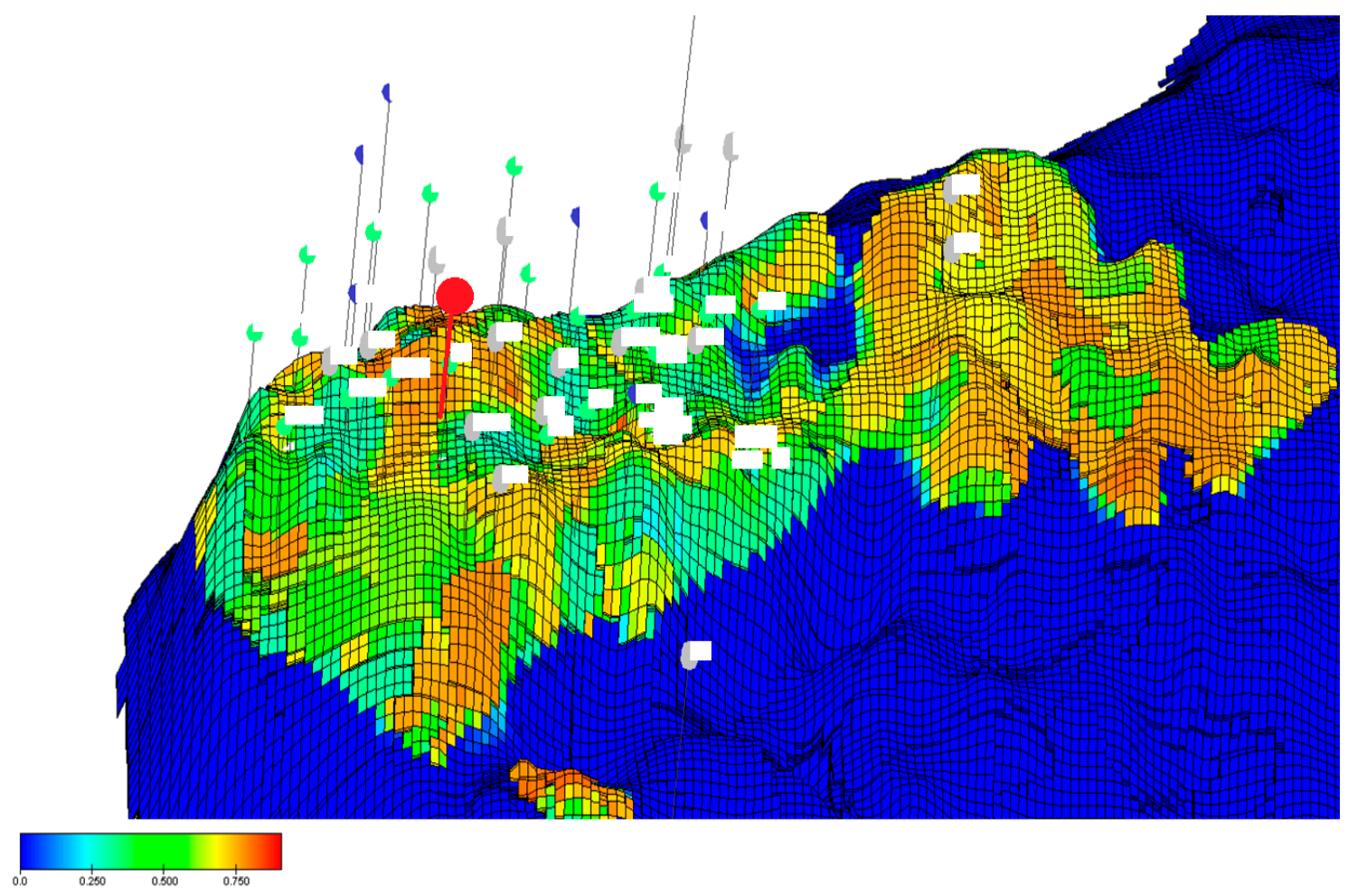

Figure 6. Illustration of the hydrodynamic model.

Table 4. Comparison of actual and predicted flow rates of the well under study.

\begin{tabular}{|c|c|c|c|c|c|c|}
\hline \multirow{2}{*}{ Date } & \multicolumn{2}{|c|}{ Oil Flow Rate, $\mathrm{m}^{3} /$ day } & \multirow{2}{*}{$\begin{array}{l}\text { Deviations in Oil } \\
\text { Flow Rate, } \%\end{array}$} & \multicolumn{2}{|c|}{ Liquid Flow Rate, $\mathrm{m}^{3} /$ day } & \multirow{2}{*}{$\begin{array}{c}\text { Deviations in } \\
\text { Liquid Flow Rate, \% }\end{array}$} \\
\hline & Actual & Design & & Actual & Design & \\
\hline June 2019 & 1.7236 & 1.7236 & - & 3.2110 & 3.2110 & - \\
\hline July 2019 & 7.4143 & 7.0612 & 4.76 & 20.9546 & 19.9949 & 4.58 \\
\hline August 2019 & 7.2705 & 6.9148 & 4.89 & 20.9147 & 19.8235 & 5.22 \\
\hline September 2019 & 7.2128 & 6.7741 & 6.08 & 20.8075 & 19.6605 & 5.51 \\
\hline October 2019 & 6.9606 & 6.6387 & 4.63 & 20.5710 & 19.5057 & 5.18 \\
\hline November. 2019 & 6.9340 & 6.5086 & 6.14 & 20.6366 & 19.3587 & 6.19 \\
\hline December. 2019 & 6.7527 & 6.3835 & 5.47 & 20.0301 & 19.2191 & 4.05 \\
\hline
\end{tabular}

According to Table 4, the predicted oil and liquid flow rates almost fully correspond to their actual values, since the average deviations were $5.33 \%$ and $5.12 \%$, respectively, while the standard deviations were 0.67 and 0.74 with variation coefficients of $12.58 \%$ and $14.47 \%$, respectively. Therefore, it is possible to note high accuracy of predicting the flow rates according to the developed technique, which will allow evaluating effectiveness of acid treatment of productive deposits that are lithologically represented by carbonate varieties.

At further calculations using the hydrodynamic model, it is possible to analyse incremental recovery of hydrocarbons for several years to come, i.e., to make a conclusion on the success of the oil recovery stimulation method. Below is the analysis of the effectiveness of the designed procedure at the target facility in comparison with the basic variant using hydrodynamic simulation; its results are given in Table 5. The calculation was conducted through 2029.

Analysing the data presented in Tables 4 and 5, we can conclude that following the acid treatment of the target oil producing well, a significant growth in oil production is expected, namely, a fourfold increase. Based on the conducted forecast, by the beginning of 2029 at the target oil producing well, the cumulative oil production will increase by 9.88 thousand $\mathrm{m}^{3}$, and the cumulative liquid production will increase by 50.25 thousand $\mathrm{m}^{3}$, following the performed HAT job. 
Table 5. Results of simulation of the basic and design variants.

\begin{tabular}{|c|c|c|c|c|c|c|c|c|}
\hline \multirow[t]{2}{*}{ Date } & \multicolumn{2}{|c|}{$\begin{array}{l}\text { Oil flow Rate, } \\
\text { m³ }^{3} / \text { day }\end{array}$} & \multicolumn{2}{|c|}{$\begin{array}{l}\text { Cumulative Oil } \\
\text { Production, Thous. } \mathrm{m}^{3}\end{array}$} & \multicolumn{2}{|c|}{$\begin{array}{l}\text { Liquid Flow Rate, } \\
\text { m³ }^{3} / \text { day }\end{array}$} & \multicolumn{2}{|c|}{$\begin{array}{c}\text { Cumulative Liquid } \\
\text { Production, Thous. } \mathrm{m}^{3}\end{array}$} \\
\hline & Basic & Design & Basic & Design & Basic & Design & Basic & Design \\
\hline January2019 & 1.7891 & 1.7891 & 49.4261 & 49.4261 & 3.2110 & 3.2110 & 59.9109 & 59.9109 \\
\hline January2020 & 1.6641 & 6.2640 & 50.0560 & 50.9784 & 3.2110 & 19.0929 & 61.0861 & 64.1740 \\
\hline January2021 & 1.5575 & 5.1407 & 50.6417 & 53.0355 & 3.2110 & 17.9362 & 62.2581 & 70.8852 \\
\hline January2022 & 1.4647 & 4.4581 & 51.1918 & 54.7637 & 3.2110 & 17.4499 & 63.4301 & 77.3300 \\
\hline January2023 & 1.3641 & 4.0507 & 51.7069 & 56.3068 & 3.2110 & 17.2217 & 64.6021 & 83.6478 \\
\hline January2024 & 1.2422 & 3.7704 & 52.1820 & 57.7304 & 3.2110 & 17.1556 & 65.7774 & 89.9339 \\
\hline January2025 & 1.1376 & 3.5840 & 52.6136 & 59.0676 & 3.2110 & 17.2215 & 66.9494 & 96.2056 \\
\hline January2026 & 1.0562 & 3.4548 & 53.0123 & 60.3496 & 3.2110 & 17.3781 & 68.1214 & 102.5209 \\
\hline January2027 & 0.9885 & 3.3365 & 53.3841 & 61.5867 & 3.2110 & 17.5682 & 69.2934 & 108.9009 \\
\hline January2028 & 0.9305 & 3.2241 & 53.7340 & 62.7857 & 3.2110 & 17.7579 & 70.4686 & 115.3689 \\
\hline January2029 & 0.8836 & 3.1110 & 54.0639 & 63.9400 & 3.2110 & 17.9399 & 71.6407 & 121.8859 \\
\hline
\end{tabular}

\section{Conclusions}

The evaluation technique of the hydrochloric acid treatment effectiveness proposed herein allows to predict the technological effectiveness of the designed procedure. The technique consists in determining the technological effectiveness using hydrodynamic simulation based on the calculated value of change in the skin factor using the initial data obtained from laboratory studies. Application of the proposed approach will allow to raise accuracy of the technical and economic assessment carried out at decision-making on conducting a geotechnical procedure. The technique also includes parameters enabling to provide recommendations on the selection of an acid composition and technology of its injection into the formation for the best effect from acid treatment of carbonate reservoirs. This approach to predicting incremental oil production was used to compare expected and actual well oil flow rates measured over 6 months of continuous operation after hydrochloric acid treatment. According to the analysis results, there is a minor error $(\approx 5 \%)$ in the predicted values and actual readings of the target well, i.e., the proposed technique of effectiveness evaluation has been successfully tested, which proves the potential of its integration in engineering activities of oil companies.

Author Contributions: Conceptualization, I.P. and S.K.; investigation, S.K., K.V., and K.R.; methodology, K.V.; project administration, I.P.; resources, K.V. and A.K.; software, A.K.; validation, A.K.; visualization, A.K. and K.R.; writing-original draft, K.V. and K.R.; and writing-review and editing, S.K. All authors have read and agreed to the published version of the manuscript.

Funding: This research was funded by the state assignment of the Ministry of Science and Higher Education of the Russian Federation as part of a government assignment, grant number FSNM-2020-0027.

Conflicts of Interest: The authors declare no conflicts of interest.

\section{Nomenclature}

$S$

$k$

$k_{d}$

$r_{d}$

$r_{w}$

$d$

Ac

$q$

D

$h$

$b$

V

$m$

$x$

skin factor

permeability coefficient of far field zone, $\mu \mathrm{M}$;

permeability coefficient of near-wellbore zone, $\mu \mathrm{m}^{2}$

drainage area radius, $\mathrm{m}$

well radius, $\mathrm{m}$

fractal dimension of pore space structure in bottom-hole zone

acid value

rate of acid composition injection, $\mathrm{m}^{3} / \mathrm{s}$

diffusion coefficient, $\mathrm{m}^{2} / \mathrm{s}$

perforated thickness of formation, $\mathrm{m}$

a constant taken as equal to $1.7 \cdot 10^{4} \mathrm{~m}^{\mathrm{d}-2}$

volume of injected acid composition, $\mathrm{m}^{3}$;

porosity, \%;

limestone content in rock, $\%$ 


$\begin{array}{ll}y & \text { dolomite content in rock, } \% \\ C & \text { molar concentration, mol/L } \\ \vartheta & \text { stoichiometric coefficient } \\ \rho & \text { density, } \mathrm{g} / \mathrm{L} \\ M & \text { molecular mass, } \mathrm{g} / \mathrm{moL} \\ k_{B} & \text { Boltzmann constant, } \mathrm{J} / \mathrm{K} \\ T & \text { absolute reservoir temperature, } \mathrm{K} \\ \mu & \text { dynamic viscosity of acid composition, Pa.s } \\ r & \text { diffusing particle radius, } \mathrm{m} \\ S_{1} & \text { skin factor before HAT } \\ Q_{1} & \text { well oil flow rate before HAT, } \mathrm{m}^{3} / \mathrm{day} \\ \Delta Q_{c u m} & \text { increase in cumulative oil production, } \mathrm{t}\end{array}$

\section{References}

1. Khizhnyak, G.P.; Amirov, A.M.; Gladkikh, E.A.; Kolesov, V.A.; Zakharyan, A.G.; Chikin, A.E.; Harris, R. Study of Acid-Generating Composition Impact on Core Samples of Productive Sediments of Kuyumbinsky License Block. Oil Ind. 2015, 3, 31-35.

2. Aidagulov, G.; Gwaba, D.; Kayumov, R.; Sultan, A.; Aly, M.; Qiu, X.; Almajed, H.; Abbad, M. Effects of Pre-Existing Fractures on Carbonate Matrix Stimulation Studied by Large-Scale Radial Acidizing Experiments. In Proceedings of the SPE Middle East Oil and Gas Show and Conference, Manama, Bahrain, 18-21 March 2019.

3. Moid, F.; Rodoplu, R.; Nutaifi, A.M.; Kayumov, R. Acid Stimulation Improvement with the Use of New Particulate Base Diverter to Improve Zonal Coverage in HPHT Carbonate Reservoirs. In Proceedings of the International Petroleum Technology Conference, Dhahran, Saudi Arabia, 13-15 January 2020.

4. Ridner, D.; Frick, T.; Zhu, D.; Hill, A.D.; Angeles, R.; Vishnumolakala, N.; Shuchart, C.E. Influence of Transport Conditions on Optimal Injection Rate for Acid Jetting in Carbonate Reservoirs. SPE Prod. Oper. 2019, 35, 137-146.

5. Sarmah, A.; Farid Ibrahim, A.; Nasr-El-Din, H.A.; Jackson, J. A Novel Cationic Polymer System That Improves Acid Diversion in Heterogeneous Carbonate Reservoirs. In Proceedings of the SPE Oil and Gas India Conference and Exhibition, Mumbai, India, 9-11 April 2019.

6. Singh, R.; Tong, S.; Panthi, K.; Mohanty, K. Stimulation of Calcite-Rich Shales Using NanoparticleMicroencapsulated Acids. SPE J. 2019, 24, 2671-2680. [CrossRef]

7. Hawkins, M.F. A note on the skin effect. J. Pet. Technol. 1956, 8, 65-66. [CrossRef]

8. Ali, M.T.; Ezzat, A.A.; Nasr-El-Din, H.A. A Model to Simulate Matrix-Acid Stimulation for Wells in Dolomite Reservoirs with Vugs and Natural Fractures. SPE J. 2019, 25. [CrossRef]

9. Abdrazakov, D.; Ziauddin, M.; Vernigora, D.; Beletskaya, A.; Yakimchuk, I.; Olennikova, O.; Usoltsev, D.; Nikolaev, M.; Panga, M.; Burlibayev, A. Integration of Latest Laboratory, Software and Retarded Acid Technologies to Increase Efficiency of Acid Treatments in Carbonates: Case Studies from Central Asia. In Proceedings of the International Petroleum Technology Conference, Beijing, China, 26-28 March 2019.

10. Hall-Thompson, B.; Ernesto, A.R.; Abdulrahman, N.; Alsuhaimi, A. Acid Stimulation-Best Practices for Design, Selection and Testing of Acid Recipes in Low Permeability Carbonate Reservoirs. In Proceedings of the International Petroleum Technology Conference, Dhahran, Saudi Arabia, 13-15 January 2020.

11. Gurbatova, I.P.; Plotnikov, V.V.; Popov, N.A.; Sysoev, I.V. Specifics of Study of Flow Properties of Oriented Core of Structurally Complex Carbonate Reservoirs. Bull. Perm Natl. Res. Polytech. Univ. Geol. Oil Gas Min. 2013, 9, 79-86.

12. Farooq, U.; Ahmed, J.; Ali, S.; Siddiqi, F.; Kazmi, S.A.A.; Mushir, K. Heterogeneity in the Petrophysical Properties of Carbonate Reservoirs in Tal Block. In Proceedings of the SPWLA 60th Annual Logging Symposium, The Woodlands, TX, USA, 15-19 June 2019.

13. Kanevskaya, R.D.; Novikov, A.V. Methods of Wormhole Simulation under Hydrochloric Acid Treatment of Carbonate Reservoirs. Oilfield Eng. 2018, 3, 19-28. [CrossRef]

14. Trushin, Y.; Aleshchenko, A.; Danilin, K.; Folomeev, A.; Haydar, A.; Gorin, A.; Sharifullin, A. Complex Approach to the Design of Acid Treatment of Carbonate Reservoirs. In Proceedings of the SPE Russian Petroleum Technology Conference, Moscow, Russia, 22-24 October 2019. 
15. Khuzin, R.; Shevko, N.; Melnikov, S. Improving Well Stimulation Technology Based on Acid Stimulation Modeling, Lab and Field Data Integration. In Proceedings of the SPE Russian Petroleum Technology Conference, Moscow, Russia, 22-24 October 2019.

16. Buijse, M.A.; Glasbergen, G. A semi-empirical model to calculate wormhole growth in carbonate acidizing. In Proceedings of the SPE Annual Technical Conference and Exhibition, Dallas, Texas, 9-12 October 2005.

17. Daccord, G.; Touboul, E.; Lenormand, R. Carbonate acidizing: Toward a quantitative model of the wormholing phenomenon. SPE Prod. Eng. 1989, 4, 63-68. [CrossRef]

18. Chordia, M.; Trivedi, J.J. Diffusion in naturally fractured reservoirs-a-review. In Proceedings of the Asia Pacific Oil and Gas Conference and Exhibition, Brisbane, Australia, 18-20 October 2010.

19. Ravelev, K.A. Comparative Analysis of Effectiveness of Acid Compositions Application for Hydrochloric Acid Treatment of Bottomhole Zone of a Carbonate Reservoir. Probl. Hydrocarb. Ore Mineral. Depos. Dev. 2019, 1, 194-196.

20. Iolchuev, A.M.; Savenyuk, O.V. Analysis of the Scale Control Method by Intermittent Injection of a Scale Inhibitor into Bottomhole Zone. Sci. Eng. Technol. (Polytech. Bull.) 2018, 4, 53-71.

21. Mishchenko, I.T. Borehole Oil Production. In Oil Gas Moscow; FGUP: Moscow, Russia, 2003.

22. Musabirov, M.K.; Dmitrieva, A.Y.; Khusainov, R.F.; Abusalimov, E.M.; Ganiev, B.G.; Ismagilov, F.Z. Increasing the Effectiveness of Foam Acid and Large-Volume Selective Treatment in the Carbonate Fields of Pao Tatneft. Oil Ind. 2019, 11, 116-119.

(C) 2020 by the authors. Licensee MDPI, Basel, Switzerland. This article is an open access article distributed under the terms and conditions of the Creative Commons Attribution (CC BY) license (http://creativecommons.org/licenses/by/4.0/). 